\title{
Editorial
}

Md. Jakaria*, Shofiul Azam, Shafayet Ahmed Siddiqui, Mohammad Injamul Hoq and Mohammad Safiqul Islam

\section{Irrational pharmacy practice and inadequate health care services in Bangladesh: a lesson learned from COVID-19 pandemic}

https://doi.org/10.1515/jbcpp-2020-0505

Bangladesh is a densely populated country in South Asia, with over 162 million people. The first case of coronavirus disease (COVID)-19 was detected in the country on Mar 8, 2020, and until Feb 09, 2021, 538,378 active cases and 8,221 death so far recorded from this deadly contagious disease [1]. The government of Bangladesh responded promptly against COVID-19 with its limited number of health professionals and resources. In this crisis moment, a greater responsibility lies on pharmacists who can play their critical roles in meeting healthcare needs by serving in pharmacy and pharmaceutical company in Bangladesh.

Pharmacists are health professionals who specialize in the rational use of medicines by practising pharmacy, including dispensing prescription drugs, monitoring drug interactions and counselling patients regarding the effects and proper usage of drugs and dietary supplements [2]. However, pharmacists are limited to only manufacturing drugs in Bangladesh, and they cannot provide other crucial services to improve the health care system. Most central government hospitals in Bangladesh have no or a few hospital pharmacists (negligible in number), and the country is yet to introduce hospital pharmacy services run by the graduate pharmacist [3]. Chinese community pharmacists played a crucial role in facing this pandemic by collaborating with communities and drug companies. They

\footnotetext{
*Corresponding author: Md. Jakaria, The Florey Institute of Neuroscience and Mental Health, The University of Melbourne, Parkville, VIC 3052, Australia, E-mail: md.jakaria@florey.edu.au. https://orcid.org/0000-0001-8216-1171

Shofiul Azam, Department of Applied Life Science \& Integrated Bioscience, Graduate School, Konkuk University, Chungju, Korea Shafayet Ahmed Siddiqui and Mohammad Safiqul Islam, Department of Pharmacy, Noakhali Science and Technology University, Noakhali, Bangladesh

Mohammad Injamul Hoq, School of Public Health, Epidemiology and Social Medicine at the Institute of Medicine, University of Gothenburg, Gothenburg, Sweden
}

offered online consultation to provide pharmaceutical and care to COVID-19 positive patients [4]. However, community pharmacy practice has not even seen in Bangladesh, leading to polypharmacy practice and dose mismanagement without knowing drug profile accurately [5]. Therefore, multidrug resistance has become a common term, and most antibiotics are becoming ineffective because of the irrational use and availability of antibiotics without prescriptions in Bangladesh [6]. Even that having a law of punishment for selling the drug without a prescription, people have regularly bought different drugs, including ivermectin, hydroxychloroquine and even dexamethasone, to prevent and treat COVID-19 reported by a newspaper in Bangladesh [7]. The absence of community pharmacy practice is the most significant cause of this condition.

Historical and empirical evidence shows the importance of hospital pharmacist in the healthcare system; their involvement eases the system and made effective by reducing drug-drug or -food interaction, raising adverseeffect related awareness and confirming proper drug application and dose. In the continuity of pharmacists responsibilities as a frontline healthcare provider, they proved their necessity in the pandemic condition and played a substantial role in ambulatory or hospitalized patient management and medication. It has been seen on some occasion that several areas remain uncovered by doctor or nurses during this pandemic. The community pharmacists have filled those gaps by serving at the ground level and providing necessary ailments to reduce the contamination at the community level. Besides, the complexity of COVID-19 infection needed multidisciplinary knowledge to manage immediate critical symptoms; again, pharmacists proved helpful to optimize patient condition by providing expertise in doses adjustment or adverseeffect reduction. In addition, pharmacists' knowledge in pharmacodynamics and pharmacokinetics can help set a combination therapy to recover or comfort critical patients. For example, many COVID-19 patients admitted to the ICU 
frequently treated with an anticoagulant, and a pharmacist could ensure proper dose requirement and avoid multiple comorbid conditions [8].

The pharmacy practice in Bangladesh and worldwide is different as pharmacists only allow to manufacture, distribute and produce drugs in Bangladesh. This limited practice made them unavailable in the major area where they needed most, and it has been suffered during the current pandemic. However, Bangladesh has promoted a developing country, but the people are still suffering from insufficient healthcare service. One of the main reasons behind that pharmacist is not involved in the mainstream. It is an urgent need for this country health ministry to realize now and allow the pharmacist to practice in hospital and community clinic. Again, the country struggled to tackle this pandemic situation because of insufficient healthcare workers, while the biggest part of this sector was left behind and avoided by the ministry. It raises two big questions, "Why pharmacists are not being allowed to work on the scenario?" "Is that the lack of knowledge of the Health Ministry?”

In neighbouring countries, pharmacists are primarily working at hospitals and clinics to ensure the proper management of disease and disorders, but pharmacists in Bangladesh are limited only in drugs manufacturing and marketing area. It could be the biggest mistake of the country when the government of Bangladesh trying to promote the healthcare system. The government and some private hospitals, with many hopes and enormous expectations, attempted to establish the hospital pharmacy in the name of "Model Pharmacy" at the country level [9]. The socalled model pharmacy was a part of the retail pharmacy; nonetheless, the biggest part of Bangladesh healthcare system, public hospitals, was not covered by this project. It was an usher for the country's pharmacist community to come to the big picture, but due to a lack of policies and guidelines, the project proved as a failure.

Rational drug use is a big challenge for Bangladesh. If we consider the pandemic situation of COVID-19, patients rarely get proper health care facilities. Limited healthcare service providers (doctors and nurses) are working in Bangladesh's health sectors, which is beyond insufficient. Thus, the management of disease and prescription counselling is questionable. The inclusion of pharmacists in the mainstream healthcare system would efficiently promote disease management and ensure rational drug practice. Policymakers such as the Ministry of Health and Family Welfare (MOHFW), the Directorate
General of Drug Administration (DGDA), the Pharmacy Council of Bangladesh (PCB) and other regulatory authorities that control education and healthcare services should take initiatives by making proper guidelines and train pharmacists in accordance to manage COVID-19 and other regular health issues. Recruiting pharmacists in the primary healthcare services would ease other service providers' workload and save many lives from the COVID-19 outbreak and during the postperiod of pandemic situation.

Research funding: None declared.

Author contributions: All authors have accepted responsibility for the entire content of this manuscript and approved its submission.

Competing interests: Authors state no conflict of interest. Informed consent: Not applicable.

Ethical approval: Not applicable.

\section{References}

1. WHO. The current COVID-19 situation in Bangladesh [Online]. Available from: https://www.who.int/countries/bgd/ [Accessed 9 Feb 2021].

2. Shao SC, Chan YY, Lin SJ, Li CY, Kao Yang YH, Chen YH, et al. Workload of pharmacists and the performance of pharmacy services. PloS One 2020;15:e0231482.

3. Paul TR, Rahman MA, Biswas M, Rashid M, Islam MAU. Practice of hospital pharmacy in Bangladesh: current perspective. Bangladesh Pharm J 2015;17:187-92.

4. Zheng S, Yang L, Zhou P, Li HB, Liu F, Zhao RS. Recommendations and guidance for providing pharmaceutical care services during COVID-19 pandemic: a China perspective. Res Social Adm Pharm 2021;17:1819-24.

5. Rakib A, Sarwar MS, Zannah S, Khanum S, Rashid M. A survey of the role of community pharmacists in Dhaka city, Bangladesh. Bangladesh Pharm J 2015;18:137-41.

6. Hoque R, Ahmed SM, Naher N, Islam MA, Rousham EK, Islam BZ, et al. Tackling antimicrobial resistance in Bangladesh: a scoping review of policy and practice in human, animal and environment sectors. PloS One 2020;15:e0227947.

7. Dhaka Tribune. Panic-buying creates shortage of 'Covid-19 drugs' in the market [Online]. Available from: https://www.dhakatribune. com/health/coronavirus/2020/06/21/panic-buying-createsshortage-of-covid-19-drugs-in-the-market [Accessed 30 Jul 2020].

8. Preslaski CR, Lat I, MacLaren R, Poston J. Pharmacist contributions as members of the multidisciplinary ICU team. Chest 2013;144: 1687-95.

9. Rahman MM, Sherin S, Jubayer AM, Islam F, Jahan N, Rahaman MS, et al. Investigation of drug distribution process and pharmacy practices on model pharmacy in Dhaka city, Bangladesh. J Drug Deliv Therapeut 2020;10:165-73. 